\title{
Metrological Analysis of Geopotential Gravity Field for Harbor Waterside Management and Water Quality Control
}

\author{
Osvaldo Faggioni, ${ }^{1,2,3}$ Maurizio Soldani, ${ }^{1}$ and Davide Andrea Leoncini ${ }^{1,2}$ \\ ${ }^{1}$ OGS (Istituto Nazionale di Oceanografia e di Geofisica Sperimentale), ST-COPS, Via Carducci 120, 19126 La Spezia, Italy \\ ${ }^{2}$ Università degli Studi di Genova, DITEN, Via all'Opera Pia 11A, 16145 Genova, Italy \\ ${ }^{3}$ Istituto Nazionale di Geofisica e Vulcanologia, Sez. Roma 2, Via di Vigna Murata 605, 00143 Roma, Italy
}

Correspondence should be addressed to Osvaldo Faggioni; ofaggioni@ogs.trieste.it

Received 24 January 2013; Accepted 22 April 2013

Academic Editor: Michela Giustiniani

Copyright (C) 2013 Osvaldo Faggioni et al. This is an open access article distributed under the Creative Commons Attribution License, which permits unrestricted use, distribution, and reproduction in any medium, provided the original work is properly cited.

\begin{abstract}
Sea level oscillations are the superposition of many contributions. In particular, tide is a sea level up-down water motion basically depending on three different phenomena: the Earth-Moon-Sun gravitational relationship, the water surface fluid reaction to atmospheric meteorological dynamic, and the Newtonian vertical adjustment of the sea surface due to atmospheric pressure variations. The first tide component (astrotide) is periodic and well known in all points of the Earth surface; the second one is directly related to the meteorological phenomenon, and then it is foreseeable; the Newtonian component, on the contrary, is not readily predictable by a general hydrostatic law, because the $J$ factor that represents the Newtonian transfer (from the atmospheric weight to the consequent sea level) is variable in each harbor area. The analysis of the gravity field permits to forecast the sea level variation due to meteorological tide events, and its metrological analysis highlights a compensation in the inverse hydrobarometric factor to be taken into account to correctly compensate atmospheric pressure variations in semibinding basins. This phenomenon has several consequences in Harbor Waterside management and in water quality control as shown by the reported case studies and introduces a new reference parameter: the so-called Water 1000.
\end{abstract}

"Dedicated to the memory of Ilaria Sanvenero" The topic of this article should have been part of a degree thesis by Ilaria, a brilliant physics student at the University of Pisa. She left us at the age of twenty-two. Here, we wish to remember Ilaria by paying public homage to her brief but precious work.

\section{Introduction}

During the last three years, the metrological observation of tide waves highlighted a phenomenon of seawater level fluctuations in port/coastal basins, strictly connected to Climate Global Change (CGC), caused by weight variations of the above atmosphere district (gravity field variations) that produce a Newtonian compensation by sea level imbalance also two time greaters than the one produced by astronomical tides; moreover, the time duration range of these phenomena is $24-120 \mathrm{~h}$.
This phenomenon is the first measured example, not extraordinary, of the direct effect of CGC on human life: in fact, metrological observations pointed out a constant increment of amplitude variation and pressure with a consequential anomalous seawater level variation in port basins (superhigh and superlow tides) with several consequences on human activities.

The phenomenon has also significant effects on the quality of port waters. From the point of view of port water quality control (WQC), the mass of seawater represents the solvent in which the pollutants components are dissolved. 
TABLE 1: Main astronomic tide components, periods, and radian frequencies (table from [15]).

\begin{tabular}{lcc}
\hline Harmonic & Period $(\mathrm{h})$ & Radian frequency $(\mathrm{rad} / \mathrm{s})$ \\
\hline $\mathrm{O}_{1}$ & 25.819 .341 & $6.7597744 E-5$ \\
$\Pi_{1}$ & 24.132 .140 & $7.2323884 E-5$ \\
$\mathrm{P}_{1}$ & 24.065 .890 & $7.2522945 E-5$ \\
$\mathrm{~S}_{1}$ & 24.000 .000 & $7.2722052 E-5$ \\
$\mathrm{~K}_{1}$ & 23.934 .469 & $7.2921158 E-5$ \\
$\mathrm{~J}_{1}$ & 23.096 .474 & $7.5560361 E-5$ \\
$2 \mathrm{~N}_{2}$ & 12.905 .374 & $1.3524049 E-4$ \\
$\eta_{2}$ & 12.871 .757 & $1.3559370 E-4$ \\
$\mathrm{~N}_{2}$ & 12.658 .348 & $1.3787969 E-4$ \\
$\nu_{2}$ & 12.626 .004 & $1.3823290 E-4$ \\
$\mathrm{M}_{2}$ & 12.420 .601 & $1.4051890 E-4$ \\
$\mathrm{~L}_{2}$ & 12.191 .620 & $1.4315810 E-4$ \\
$\mathrm{~T}_{2}$ & 12.016 .449 & $1.4524500 E-4$ \\
$\mathrm{~S}_{2}$ & 12.000 .000 & $1.4544410 E-4$ \\
$\mathrm{R}_{2}$ & 11.983595 & $1.4564320 E-4$ \\
$\mathrm{~K}_{2}$ & 11.967 .234 & $1.4584231 E-4$ \\
$\mathrm{M}_{4}$ & 6.210 .300 & $2.8103780 E-4$ \\
$\mathrm{MS}_{4}$ & 61.033 .392 & $2.8596300 E-4$ \\
\hline
\end{tabular}

The density of this solution depends on the amount of the solute (pollutants) and on the mass of the solvent (seawater). In high pressure conditions, the mass of water can be greatly decreased, and then the solution seawater pollutant may increase its density significantly also without any increment of the solute (chemical and physical pollutants). Obviously, in the case of low atmospheric pressure, the opposite occurs (increment of the mass of water and consequent decrement of the density of the pollutants without diminution of their mass in the solution). In order to have a correct and comparable series of measures for WQC, it is therefore necessary to introduce a reference level called Water 1000 (W1000) in order to normalize the density values of the pollutants measured at any atmospheric pressure to those corresponding to an atmospheric pressure of about $1000 \mathrm{hPa}$. This is possible by means of a parameter $(J)$ that connects the pressure variation atmospheric to the variation of mass of port water.

The capability of prediction of harbor water level permits moreover to improve the effectiveness of safety in port navigation and security provided by underwater port protection systems.

Indeed, port basins usually host key infrastructures and are at the same time strategic points for maritime transportation: for these reasons, ports should be able to protect themselves and their infrastructures from damage, destruction, or disruption by natural disasters, deliberate acts of terrorism, negligence, and so forth.

The paper is composed of four sections. After a short introduction in Section 2, there are reported theoretical considerations on gravity field and its metrological analysis, in particular, Section 2.3 discusses the safety and security issues in which the phenomenon is involved and points out the HWSM and WQC consequences due to the analyzed phenomenon. Section 3 reports two different case studies in different geographical areas with several interesting aspects addressed in the paper, and then conclusions and possible future works follow.

The purposes of this work are to develop a quantitative method for the forecasting of the flow times and amplitude of meteorological tides (meteotides), based on the joined use of barometers, hydrometers, and clocks, describe a preliminary law of meteo-tide parameters studying the meteotides as adjustment of the geodetic surface (free sea surface), and present the first results on HWSM and WQC based on meteotide forecasting.

\section{Materials and Methods}

2.1. The Tide Phenomenon and Its Components. The term "tide" derives from the German "tiet" which means "time": indeed, this term is used commonly to indicate the phenomenon of rise and fall of sea level [1] caused by the combined effects of periodic gravitational forces exerted by the Moon, the Sun, and the rotation of the Earth. In general, this definition is correct only at a first analysis: in fact, this definition concerns only the astronomical component of this kind of phenomenon (primary contributes) without taking into account other gravitational forces (secondary contributes) usually aperiodic.

The astronomical component can be easily described by a Fourier analysis, both in its elementary (fundamental) components and in the composed harmonics resulting from interference among the fundamental waves themselves. The harmonic sinusoidal tide components have specific amplitude depending on the site of observation and are characterized by typical and recurrent frequencies (see Table 1).

The Rete Mareografica Nazionale (RMN), managed by the Istituto Superiore per la Protezione e la Ricerca Ambientale (ISPRA)-Servizio Mareografico Nazionale (SMN), provides a coverage of the Italian coasts that effectively monitors sea level fluctuations. The harmonic analysis of these data underlines both the presence of the fundamental tide components and the composed ones (also named overtides) that cover an important role in the sea level fluctuations of shallow water (M4 and MS4; see Table 1).

Together with these contributions (primary contributions), there are some sea level fluctuations not related to the classical tide concept but due to other climatic agents such as wind action (i.e., storm surges) [2], pressure variations of thermal origin (e.g., alternation night-day), local morphology of the environment (i.e., seiches and coastal trapped wave), and aperiodic low-frequency sea level fluctuations (due to meteorological pressure variations) representing the background level on which astronomic components overlap (secondary contributions) [3-7].

All the secondary contributions-except sea level fluctuations due to meteorological pressure variations-have been widely analyzed in the literature and are characterized by phenomena which are easy to note and to forecast. The paper focuses the attention to the forecasting of the sea level fluctuations due to meteorological pressure variations because of its novelty. 


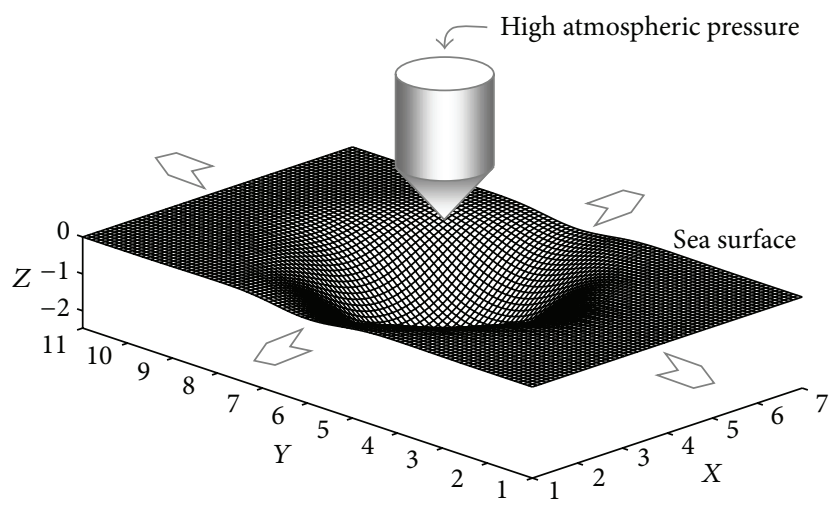

$\sum$ Water flow out

Scale units

$X \mathrm{Km} \mathrm{e}^{2} ; Y \mathrm{Km} \mathrm{e}^{2} ; Z \mathrm{Km} \mathrm{e}^{-4}$

FIGURE 1: Picture of the geodetic phenomenon of sea level deformation due to atmosphere weight (image from [15]).

These fluctuations depend in a variable way on the transit of atmospheric fronts or, in general, on the atmosphere meteorological dynamics over the considered sea basin [8] and hence cannot be predicted by harmonic analysis [9-14].

When a high-pressure air front moves on a free water surface, it originates an additional weight on it. The isostatic reaction of free water surface is a concave adjustment with respect to the starting surface (see Figure 1) to compensate, in the local atmosphere-water column, the increase in atmosphere weight with a water outflow (low meteo-tide).

On the contrary, when a perturbed front produces a drop in atmosphere weight, the isostatic compensation adjustment will be realized in a bump produced by a flow of incoming tide (high meteo-tide).

The time between the pressure inbalance and its Newtonian compensation is called "tide inertness".

2.2. Metrological Analysis of the Geopotential Gravity Field. Starting from these considerations a local atmospheric variation produces a meteotides flow that consists in an adjustment of the free sea surface. When the sea level is in isostatic equilibrium with atmosphere weight, tide fluctuations concern only astronomic components. When an atmospheric weight variation occurs, the sea surface reacts by a lowfrequency fluctuation reaching a new equilibrium state.

Such adjustment is characterized by a delay time due to the different dynamic responses of atmosphere compared with seawater. This delay cannot be evaluated with a theoretical law on the basis of barometric measurements. Meteo-tide flow and reflow times, in fact, feel the effects of many local factors: the most important being coast and bottom morphology and, secondly, the currents, the wind, and seawater density.

On the contrary, if a gravimetric anomaly signal is detectable, the force producing the beginning of a meteotide event will be technically measurable before the beginning of the sea surface compensation related to the barometric variations. The weight change of the mass which induces the change of atmospheric pressure at sea level is due, in first approximation, to three types of contributions. The contribution of the first order is the density of the volume of the considered atmosphere (the mass of air present in the local column of atmosphere) which in turn also depends on chemical-physical characteristics of the mixture of air considered (essentially humidity) and on its meteorological dynamic state (down force kinetic-principle of Bernoulli), respectively, second and third order. However, regardless of the causes of inducing phenomenon, an atmospheric weight increment always induces a Newtonian adjustment in the sea surface. For this evidence, the metrological approach, correlating atmospheric weight variations to the inverse geodetical sea level variations, is fully consistent with the quantitative definition of the relationship between the phenomena. When the cause (high pressure) generating such adjustment stops, the sea surface is in geopotential unbalanced conditions and produces a gravimetric anomaly inducing a Newtonian water flow to compensate this imbalance (returning to the sea surface geometry preceding the increase of pressure), as a propagating tide wave. Then, using a barometer near the meteomareographic station provides an essential preliminary datum, since such instrument (if sensitive to the phenomenon) is able to measure the Newtonian signal of geodetic imbalance when it occurs. If a tide gauge is joined to the barometer, the sea level measurement and the meteo-tide wave arrival time can be achieved. The difference between barometric maximum time and meteo-tide wave arrival time (i.e., the delay between the Newtonian generating cause and the geodetic reaction) is the meteo-tide time of flow (or reflux). A reasoned statistic of these measurements is able to provide the law of meteo-tide delay based on the entity of the Newtonian generating push. Such law, characteristic of every harbor, will become the barometric measure predictors of meteo-tide delay time. Another critical aspect of this phenomenon is represented by its persistence on the local region. Indeed while astronomical tides have an influence time period in the order of some hours, a meteo-tide event could affect the area also for some days.

This phenomenon is well known in the literature [16$18]$ and is called Inverted Barometer (IB) effect. The simplest approximated correction that could be done consists in considering a purely local response of the sea surface to atmospheric pressure at the measurement point. The inverse barometer correction can be easily computed from the dry troposphere correction [19]:

$$
\mathrm{IB}[\mathrm{mm}]=-9.948 *\left(\Delta R_{\mathrm{dry}}[\mathrm{m} \text { bars }]-1013.3\right) .
$$

To $1 \mathrm{hPa}$ of variation of atmospheric pressure corresponds a linear response of the sea level of about $1 \mathrm{~cm}$. This simplified condition, which represents the state of the art in meteo-tide analysis, is true in offshore areas where there are no physical constraints. Vice versa in port basins or in coastal areas, the presence of natural and manmade structural constraints such as rocks, cliffs, pier, and dock structures forces the exciding free volume of water to reflow outside the basin. This isostatic reaction implies a significant modification to the IB effect 


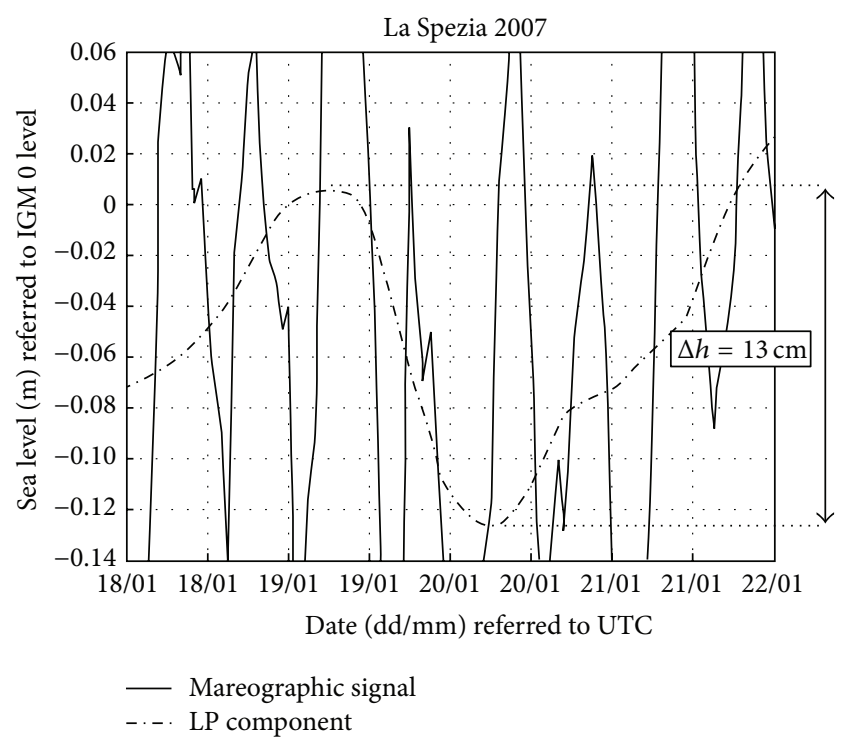

FIGURE 2: The mareographic signal recorded by La Spezia Newtonian Meteo-tide Station between 18.01.2007 and 22.01.2007 and its low pass component, $F_{c}=10^{-5} \mathrm{~Hz}$ (image from [15]).

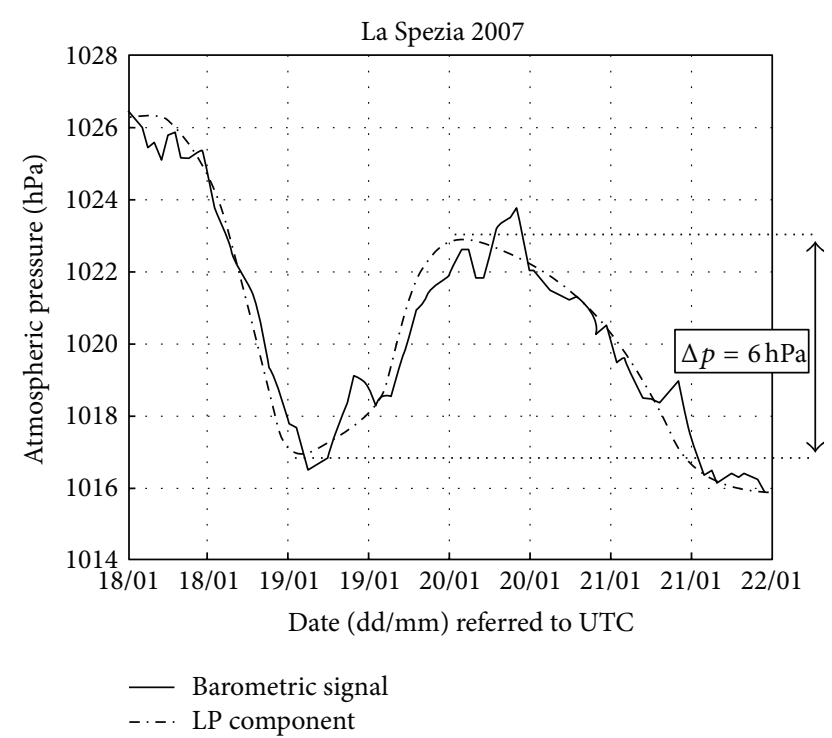

FIgURE 3: The barometric signal recorded by La Spezia Newtonian Meteo-tide Station between 18.01.2007 and 22.01.2007 and its low pass component, $F_{c}=10^{-5} \mathrm{~Hz}$ (image from [15]).

introducing a new forecasting parameter in port areas: the inverse hydrobarometric factor $(J)[3,15,19]$.

2.2.1. The Hydrobarometric Factor $(J)$ as Atmospheric Pressure-Port Water Sea Level Transfer Factor. The starting point to perform a meteo-tide forecasting analysis in port basins is to detect a statistic relationship between atmospheric pressure and sea level variations. By this way, the low-frequency components of barometric and mareographic signals grabbed during several events and occurred in last years have been compared. The cut off frequency $F_{c}$ has been determined in order to separate low-frequency band (meteotide due to Newtonian phenomena) from high-frequency band (astronomical tide and sea wave phenomena) and is equal to $10^{-5} \mathrm{~Hz}$.

In particular, the $J$ factor was calculated for each studied event, according to the following formula:

$$
J=\left|\frac{\Delta h}{\Delta p}\right|
$$

in which $\Delta h$ represents the low pass component variation of the sea level and $\Delta p$ the low pass component variation of the atmospheric pressure. To explain the developed method to calculate $J$, we analyze the event from 18.01.2007 to 22.01.2007 in the La Spezia harbor (see Figures 2 and 3). During the analyzed event, the atmospheric pressure increased to $6 \mathrm{hPa}$ $(\Delta p=6 \mathrm{hPa})$ while the port water sea level decreased by $13 \mathrm{~cm}(\Delta h=-13 \mathrm{~cm})$.

By this way, the phenomenon could be characterized by a $J$ factor computed as follow:

$$
J=\left|\frac{\Delta h}{\Delta p}\right| \approx \frac{13}{6} \frac{\mathrm{cm}}{\mathrm{hPa}} \approx 2.2 \frac{\mathrm{cm}}{\mathrm{hPa}} .
$$

This means that every increase of $1 \mathrm{hPa}$ in atmospheric pressure was followed by a decrease in sea level of about $2.2 \mathrm{~cm}$. The computation of the $J$ factor was repeated for several significant events occurred during 2007 in the La Spezia harbor obtaining a $J$ factor value for each event. So, it was possible to calculate an estimated $\widehat{J}$ value by an extensive statistic of $J$ factor:

$$
\widehat{J} \approx 2 \frac{\mathrm{cm}}{\mathrm{hPa}} .
$$

A correct estimation of the key parameter $\widehat{J}$ allows the conversion of an atmospheric pressure variation into an expected sea level increase/decrease in the considered basin:

$$
\Delta \widetilde{h}=-\widehat{J} * \Delta p,
$$

where $\Delta \widetilde{h}$ is the sea level expected variation, $\widehat{J}$ is the estimated hydrobarometric factor, and $\Delta p$ is the measured pressure variation.

These results indicate an opposite trend sea level variation of about $2 \mathrm{~cm}$ for any atmospheric pressure variation of $1 \mathrm{hPa}$ in the Port of La Spezia. The described forecasting method error (difference between the expected sea level and the observed one) did not exceed $5 \mathrm{~cm}$ in the Port of La Spezia during 2007.

The same statistical analysis performed during last years in other Italian ports (see Table 2 ) shows that $\widehat{J}$ ranges from $1.6 \mathrm{~cm} / \mathrm{hPa}$ to greater than $2 \mathrm{~cm} / \mathrm{hPa}$ (depending on the port), while it values about $1 \mathrm{~cm} / \mathrm{hPa}$ in the offshore areas according to the IB effect law.

2.2.2. Meteotide Inertness. Geometrical comparison between low-frequency components of the two signals shows that a time $\Delta t \approx 10 \mathrm{~h}$ elapses between atmospheric pressure minimum time (19/01 00:00) and corresponding sea level 
TABLE 2: Inverse hydro-barometric factor $(J)$ estimation in different Italian ports-one year observation.

\begin{tabular}{lc}
\hline Gulf & $J(\mathrm{~cm} / \mathrm{hPa})$ \\
\hline La Spezia & 1.9 \\
Genova & 1.8 \\
Marina di Carrara & 1.7 \\
Piombino & 1.8 \\
Civitavecchia & 1.6 \\
Livorno & 1.9 \\
Ancona & 1.8 \\
Bari & 1.6 \\
Ravenna & 2.2 \\
\hline
\end{tabular}

maximum time (19/01 10:00; meteomareographic flux). Such delay could be also identified between atmospheric pressure maximum time (19/01 22:00) and sea level minimum time (20/01 08:00; meteomareographic reflux): variation of atmospheric pressure and consequent opposite variation of sea level shifted each other by nearly $10 \mathrm{~h}$. This delay represents, for these events, the inertness of water mass moving in reply to Newtonian pulse generated by variation of atmospheric pressure. In general, the same temporal analysis performed in Italian ports shows an inertness range from $10 \mathrm{~h}$ to $18 \mathrm{~h}$.

\subsubsection{Meteotide Forecasting in Port Basins and Its Conse-} quences. Starting from these considerations, it is interesting to notice that the amplitudes of maxima meteo-tide waves (briefly named meteotides) are sensitively greater than astronomical tide waves (astrotides). This phenomenon is typical in several Italian ports (see Table 2), where the merchant and military harbor structures are subject, under unxceptional meteorological conditions, to low-frequency meteotide flows showing an amplitude even four times greater than normal astrotide amplitudes (i.e., Port of Ravenna). Therefore, the importance of forecasting the meteo-tide flows is remarkable for safety and security reasons and should be taken into account in HWSM rules and in HWQ controls.

Moreover, with the increase of occurrences of local atmospheric variations due to the Climate Global Change (CGC), also the occurrences of this phenomenon have increased (i.e., in Marina di Carrara, Livorno, Piombino, and Civitavecchia harbors; see Figures 4(a), 4(b), 4(c), and 4(d)) producing a direct impact on port and coastal ecosystems including human activities. The phenomenon is detectable in all coast sectors we are monitoring (North Tyrrhenian Sea, see Figure 5).

2.3. Effects of Newtonian Meteotide in Port Environment. The knowledge and prediction capability of the hydrobarometric tide waves dynamics produce a relevant increase in local safety and security HWSM and HWQ controls and in sea structure port design. As reported in the previous paragraphs, the flow times and amplitudes of meteotides unlike the astrotides are not easily predictable because of the stochastic nature of the atmospheric dynamics and because of the complex correlation between atmospheric pressure variation and consequent sea surface adjustment (related to temporal phase displacement and amplitude variations).

However, the advent of numerical modelling and the use of air-wave-ocean coupled systems have been improving a lot the forecasting skills of atmospheric pressure [20-28].

Independently by the accuracy and reliability of these methods, port authorities could obtain a forecasting of the sea level of the first order considering the pressure measured at the current time and considering the inertness of the sea volume. By this way, they obtain forecasting capabilities of a certain (because it has been measured) sea level variation. Moreover, using a numerical model able to forecast the atmospheric pressure variations, it is possible to introduce a second order forecasting longer in the delay time but uncertain and with lesser reliability.

Only taking into account the concept reported in Sections 1 and 2, it is possible to provide an effective parameter in environmental HWSM (in particular regarding nautical traffic) and in HWQ controls. The knowledge of such phenomenon makes it possible to define the resistive capacity of the harbor/basin to environmental impact. Moreover, it makes it possible to plan human activities in the harbor waters according to the stress condition of the area. As an example, if a dredging operation or any other intrusive action in shallow waters should be performed in an harbor basin, the statistical knowledge of the seasonal period of maximum water exchange and the ability to forecast the exchange times will be decisive in minimization of environmental impact. Indeed they can provide some crucial indications on the best time for works execution.

2.3.1. Safety Aspects. The capability of prediction of real harbor water surface level permits to improve the effectiveness of safety in the port navigation and water quality control and in sea structure port design and implementation. A first evidence related to port navigation safety is represented by the Moby Rider ship. The complete analysis is reported in Section 3.

The environmental water quality in port areas is often monitored with many chemical-physical controls, especially in the harbors in which, in addition to the normal human and port activities (not particularly high pollution values without considering accidental events), there are also industrial activities. The density of the pollutants, for both chemical and physical aspects (e.g. increase of temperature due to industrial cooling waters downloaded into the sea), does not depend only on the introduced solute but also on the quantity of solvent (seawater) present in the harbor during the same flow. Meteobaric tides have a role more important than astronomic tides in the formation of the port watery solution because beyond their amplitude, they are often very persistent for several days. So, for the same quantity of introduced solute, they govern the final density of the solution (adding or extracting solvent). For the same quantity of pollutants introduced in the sea basin, a sampling without correlation to the reading of the meteobaric tide amplitude can overestimate or underestimate the environmental waters quality. The meteobaric tides forecasting furnishes the real quantity of 


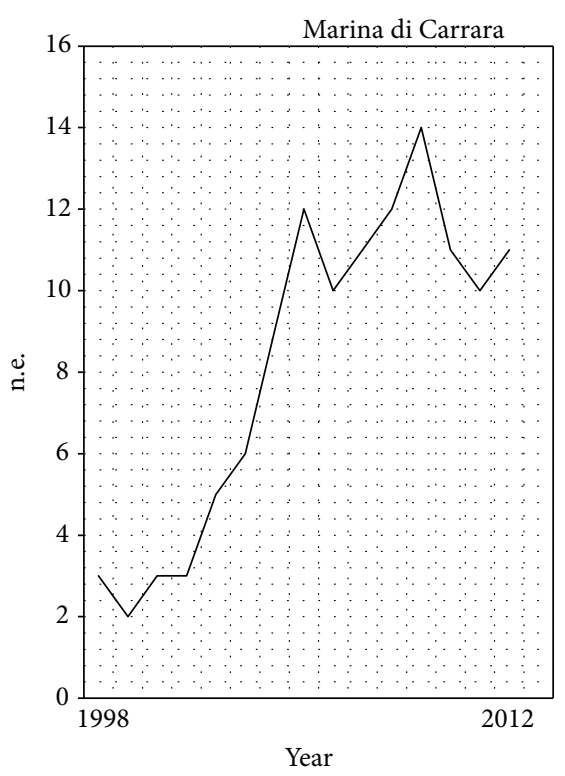

(a)

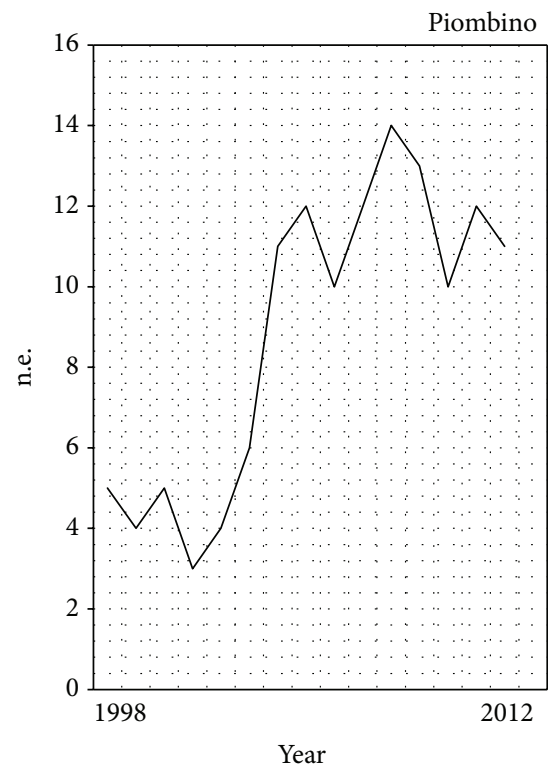

(c)

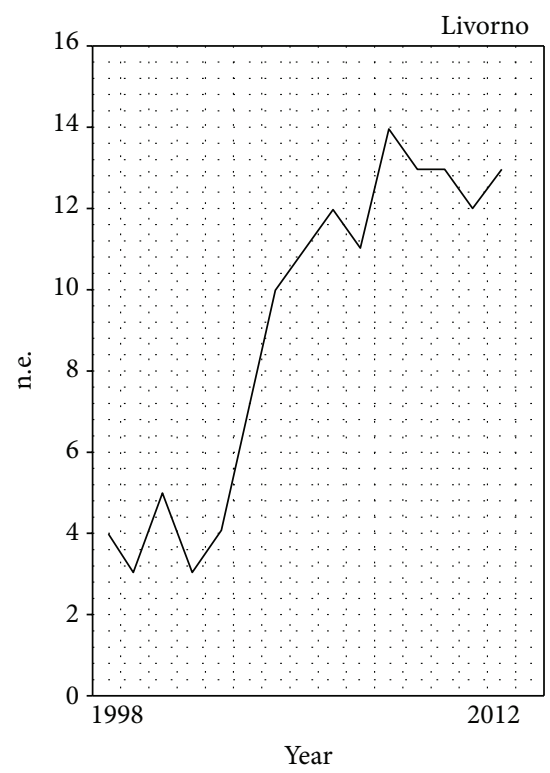

(b)

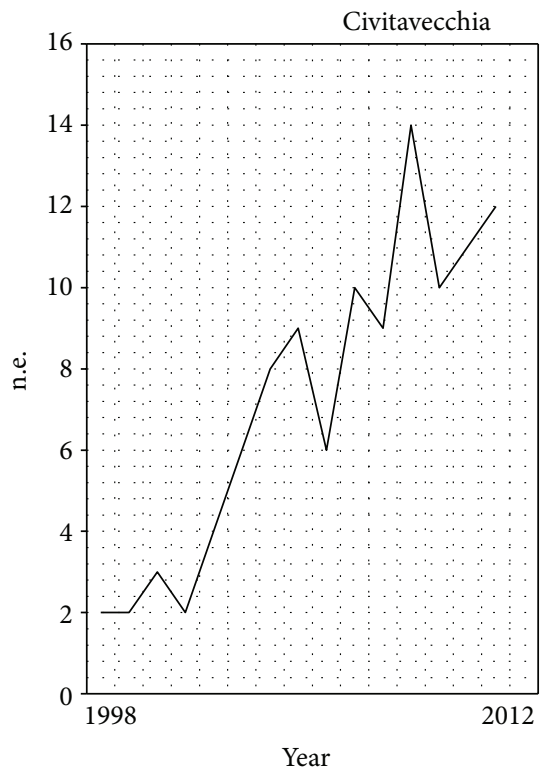

(d)

FIGURE 4: Occurrences from 1998 to 2012 of Newtonian meteotides events in Marina di Carrara, Livorno, Piombino, and Civitavecchia (n.e. number of events).

solvent present in the harbor (seawater) during sampling and therefore the possibility to set the environmental surveys to the normalized water (W1000-port sea level at $1013 \mathrm{hPa}$ of atmospheric pressure) making them comparable among them.

2.3.2. The W1000 Concept. The duration and the amplitude of the port hydrobarometric tidal waves can interfere significantly on the port water quality altering the solute-solvent mass ratio. Defining with $X$ a hypothetical pollutant, the water quality with respect to the mentioned pollutant is the concentration of $X$ in the water solution of the port where the solvent is represented by the seawater. The concentration of the solution is thus a function of the mass of solute $X$ and of the mass of seawater. The result is that there is no univocal relationship between the quantity of pollutant dissolved and the quality of the solution.

In conditions of persistent high pressure, the harbor basins of Table 2 are emptied of water also in an intense and long-lasting way (usually equal to a few percentage points and sometimes more), and then the concentration of the solution is altered by the decrease of solvent and not by the increase of pollutant. 


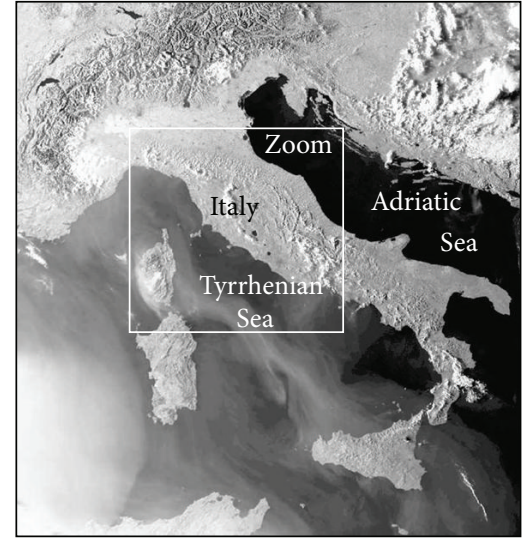

(a)

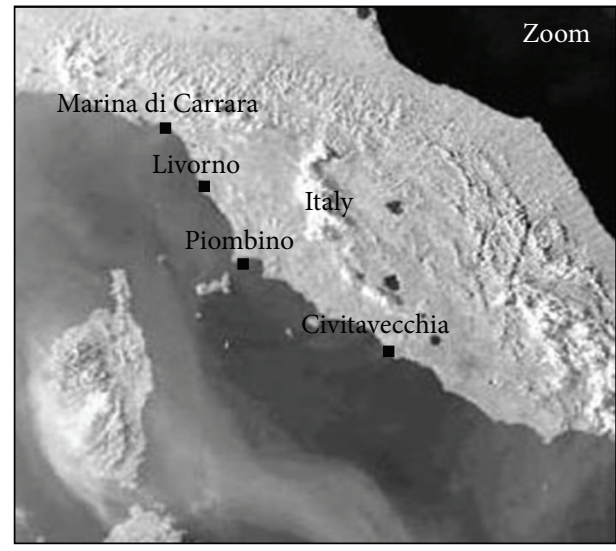

(b)

Figure 5: North Tyrrhenian Sea map with analyzed harbor localizations.

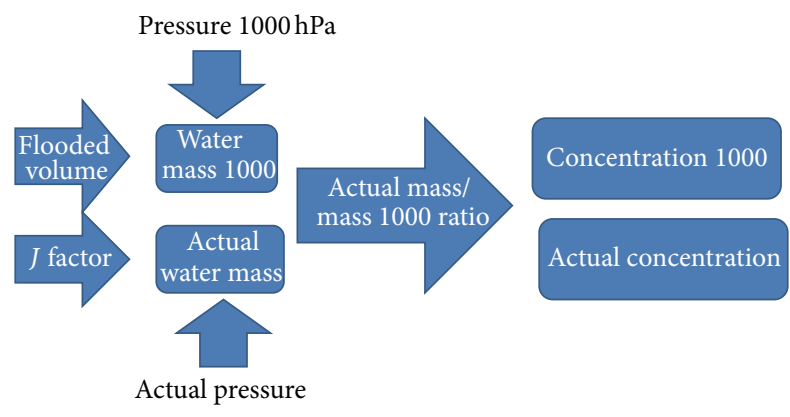

FIGURE 6: W1000 and actual concentration computation (algorithmic scheme).

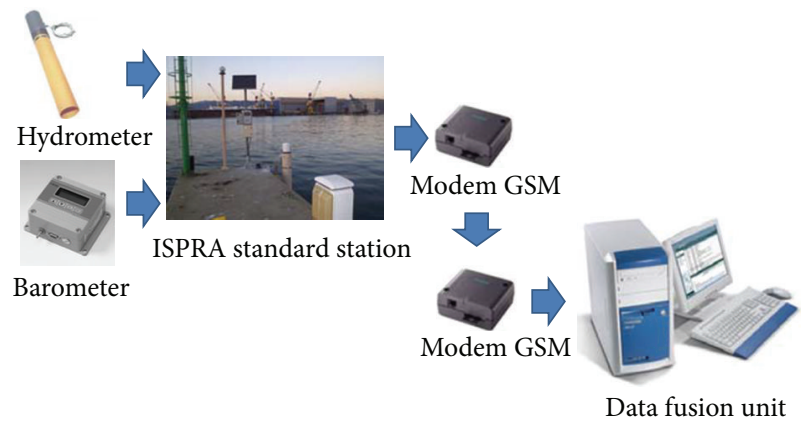

FIGURE 7: ISPRA standard meteomareographic station (La Spezia ISPRA station schematic).

This environmental dependence of the concentration of the solution alters the information on the intensity of the anthropic pressure on the environment itself and above all makes metrologically not comparable successive measurements because the only density measurement of the chemical solution does not inform about the amount of solvent. Obviously, in conditions of persistent high atmospheric pressures, the measurements of the quality of port water tend to be overestimated (compared to the quantity of pollutant). Vice versa in conditions of low atmospheric pressures and thus

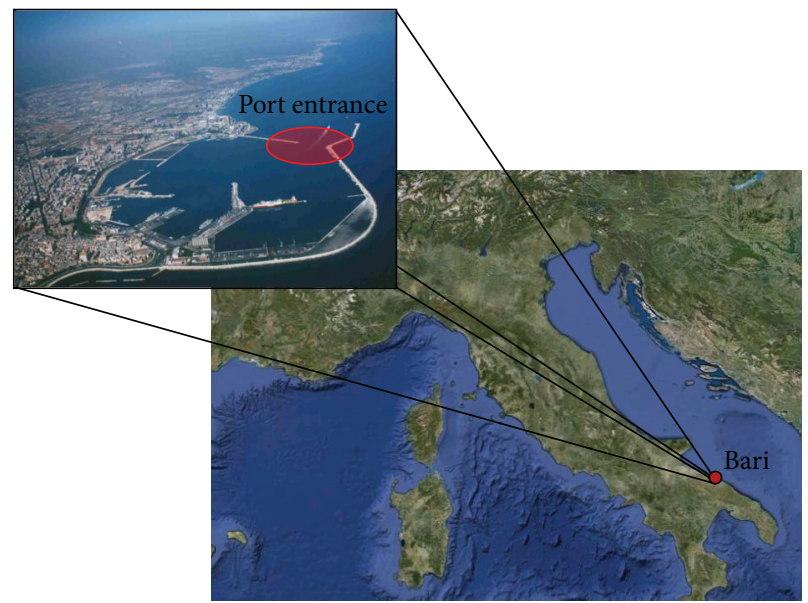

FIgURE 8: Port of Bari and in particular the port entrance (Image from Google Maps).

superfilling, the measurements of port waters environmental quality will lead to an underestimation of the amount of the pollutant in the solution.

This serious drawback (fatal from a metrological point of view) makes random the comparison between successive measurements of harbor water quality (worse in the control of the mass of solvent). To overcome this problem it is possible to introduce the W1000 concept.

By means of the $J$ factor, it is possible to estimate the mass of water in the port under investigation (for which you know the volume of flooded) at any atmospheric pressure conditions at the time of measurement. By this way, it is possible to calculate the percentage ratio of the change in mass of solvent from the atmospheric conditions of measurement to those of W1000, and it is possible to compensate the concentration of the solution with respect to the mass changing of solvent. The port water quality samples will then give two answers: the overall concentration and the W1000 concentration (see Figure 6). 


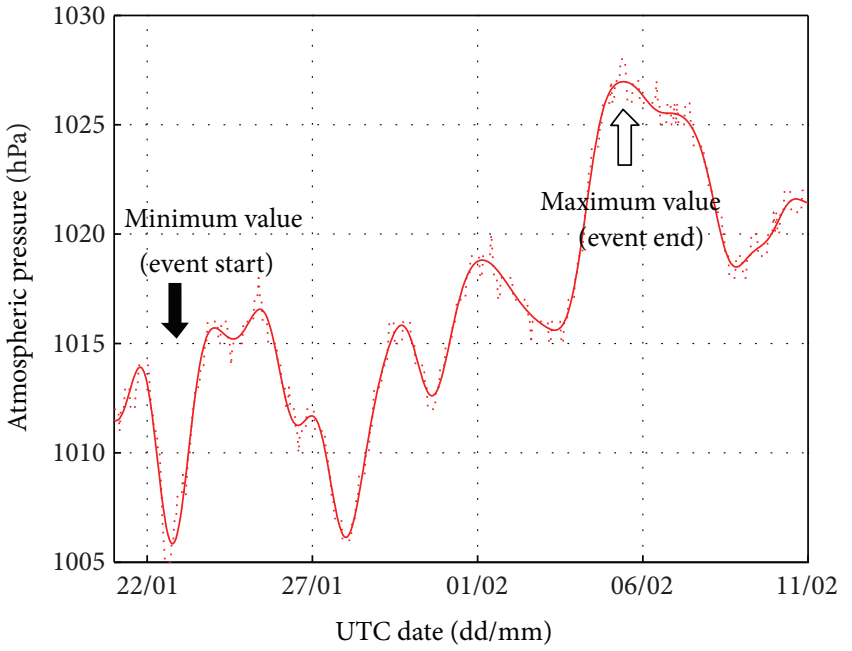

(a)

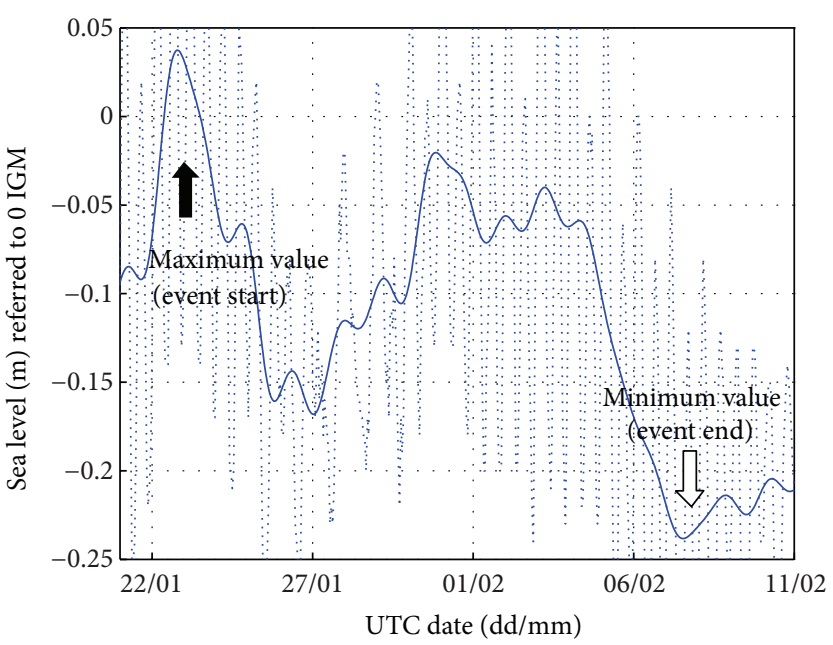

(b)

Figure 9: Port of Bari atmospheric pressure and sea level during February 2010 meteo-tide event (dotted line: high frequency, continue line: low frequency, $F_{c}=10^{-5} \mathrm{~Hz}$ ).

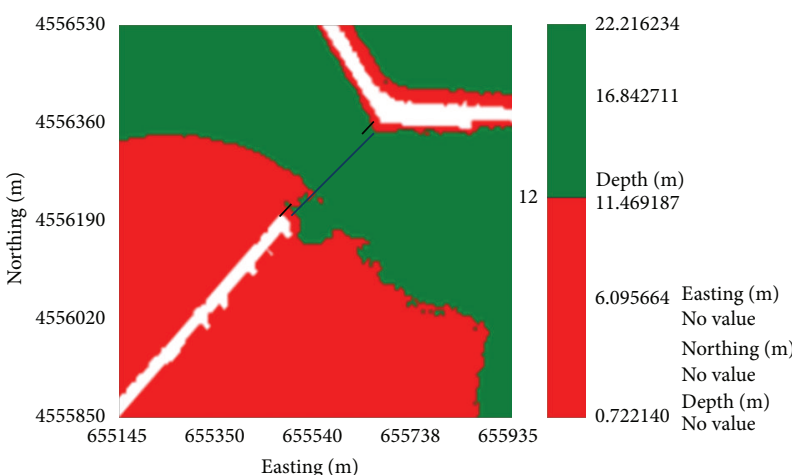

(a)

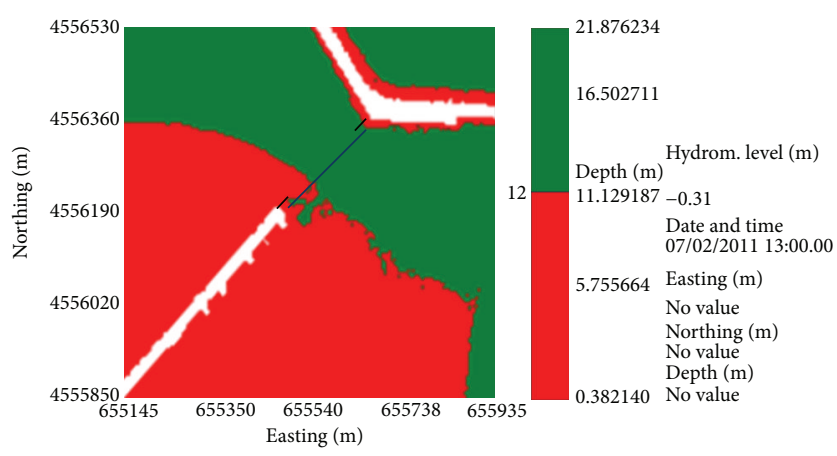

(c)

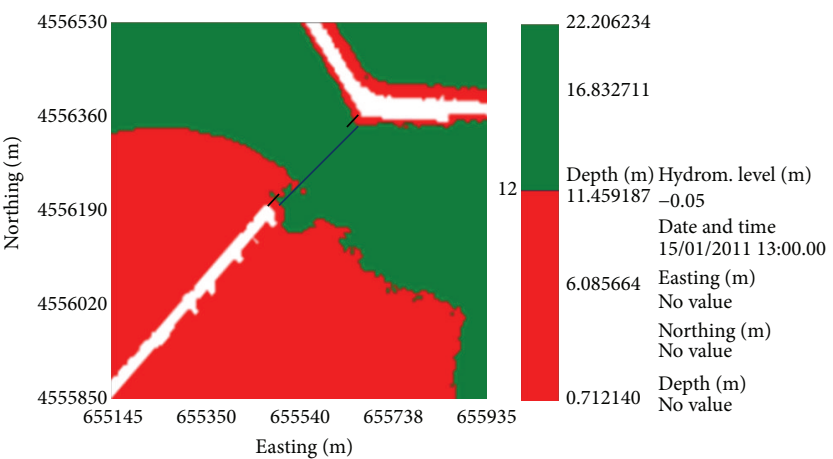

(b)

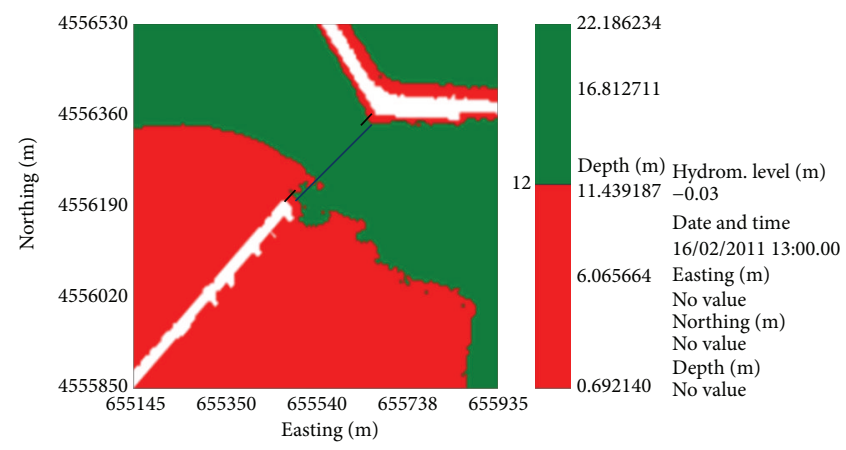

(d)

Figure 10: Dynamic bathymetry of Port of Bari. The blue line represents the acoustic subsystem while the two black lines represent the magnetic subsystem. Red areas are zones with water depth under $12 \mathrm{~m}$ (not controllable with acoustic subsystem configured with operative quote of $12 \mathrm{~m}$ ) while green areas are zones with water depth above $12 \mathrm{~m}$. (a) represent the static analysis of the area, (b) the area before the event, (c) during the event, and (d) after the event. 


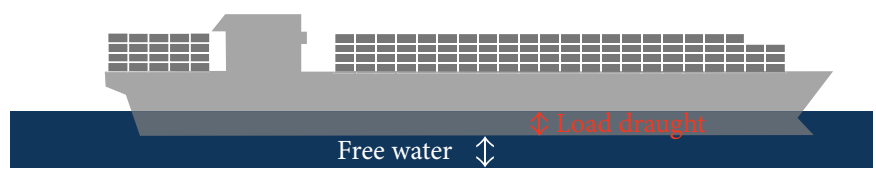

(a)

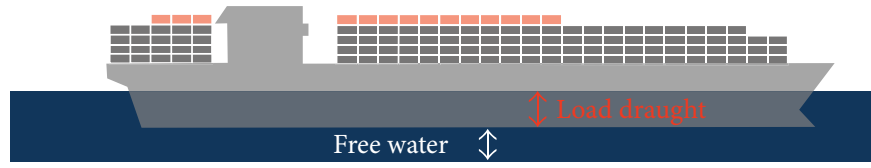

(b)

$\begin{array}{ll}\text { Atm pressure: } & 1025(\mathrm{hPa}) \\ \text { Sea level: } & 10(\mathrm{~m}) \\ \text { Charge: } & 2750 \mathrm{TEU} \\ \text { Free water: } & 0.5(\mathrm{~m}) \\ \text { Load draught: } & 9.5(\mathrm{~m})\end{array}$

Atm pressure: $990(\mathrm{hPa})$

Sea level: $\quad 11(\mathrm{~m})$

Charge: $\quad 3200 \mathrm{TEU}$

Free water: $\quad 0.5(\mathrm{~m})$

Load draught: $10.5(\mathrm{~m})$

FIGURE 11: Difference of payload in TEU during two different atmospheric pressure situations.

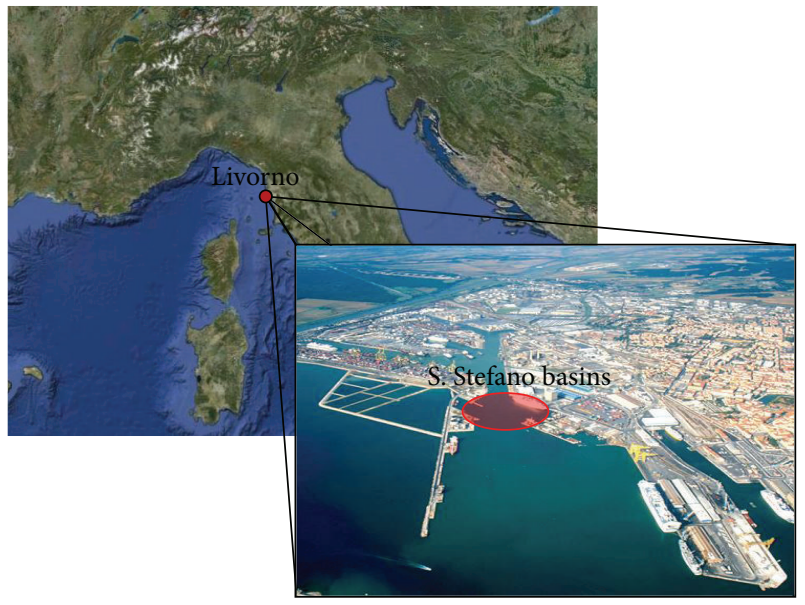

FIgURE 12: Port of Livorno and in particular S. Stefano basin locations (image from Google Maps).

The atmospheric pressure is not the only environmental factor that affect measurements of harbor water quality control. Other factors (secondary contributions with respect to the ones produced by atmospheric pressure because they produce sea level variations of low intensity) include but are not limited to various water sources such as precipitation or evaporation phenomena and river and dispersed freshwater inputs. Nevertheless, these kinds of factors can be interesting for high definition analysis but irrelevant for the HWSM.

However, the W1000 problem is solved from a geodetic point of view by the definition of the $J$ factor at first approximation and with secondary contribution only in higher approximations.

\section{Results and Discussion}

Every port in Table 2 has been equipped with an ISPRA meteomareographic station. The standard configuration includes one microwave hydrometer, one digital barometer, one GPS module, and one GSM module for data transmission (see Figure 7).
Using a standard station, it is possible to estimate the atmospheric air mass variation on the observed area and then to identify a meteo-tide event.

3.1. Port of Bari. The first example is a generic observation of a specific meteo-tide event and their possible consequences in Port of Bari (see Figure 8). In particular in February 2010, considering only the effect of meteo-tide (low frequency signal), an atmospheric pressure variation of about $21 \mathrm{hPa}$ produced a diminution of sea level of about $28 \mathrm{~cm}$ (see Figure 9, white arrow). Simulating the event, it is interesting to notice that the sea level variation in $07 / 02 / 2011$ at 13:00 (date of the maximum sea level variation) is of $-0.33 \mathrm{~m}$ (see Figure 10(c)). The astronomic tide from tide tables in the same time is of about $-0.05 \mathrm{~m}$ while the meteo-tide is of about $-0.28 \mathrm{~m}$ (as previously seen). This highlights the right considerations on meteo-tide effect. Starting from these considerations, it is also possible to compute the inverse hydrobarometric $J$ factor for the analyzed event:

$$
J=\left|\frac{\Delta h}{\Delta p}\right| \approx \frac{28}{21} \frac{\mathrm{cm}}{\mathrm{hPa}} \approx 1.3 \frac{\mathrm{cm}}{\mathrm{hPa}} .
$$

Another interesting aspects to point out is that the effect of the sea level variation takes place one hour later compared to the pressure variation beginning (identified by the black arrows in Figure 9), but the delay increases until becoming equal to some days (see white arrow in Figure 9).

Once analyzed one example of meteo-tide occurrence and its effects on the basin water volume, it could be interesting to investigate some possible issues caused by this phenomenon.

To avoid intrusion in Bari harbour, it is possible to displace an acoustic/electromagnetic barrier on the sea bottom in the port entrance. The water depth in quite condition in the specific area is of about 12 meters so the acoustic active subsystem could be configured with a maximum range of $12 \mathrm{~m}$. By this way, if the sea level grows, it could be possible for a diver to enter the area without being detected passing at a sea floor distance greater than $12 \mathrm{~m}$. Vice versa if the sea level falls down, the reverberation noise produced by the reflection caused by the sea surface could increase making blind the 


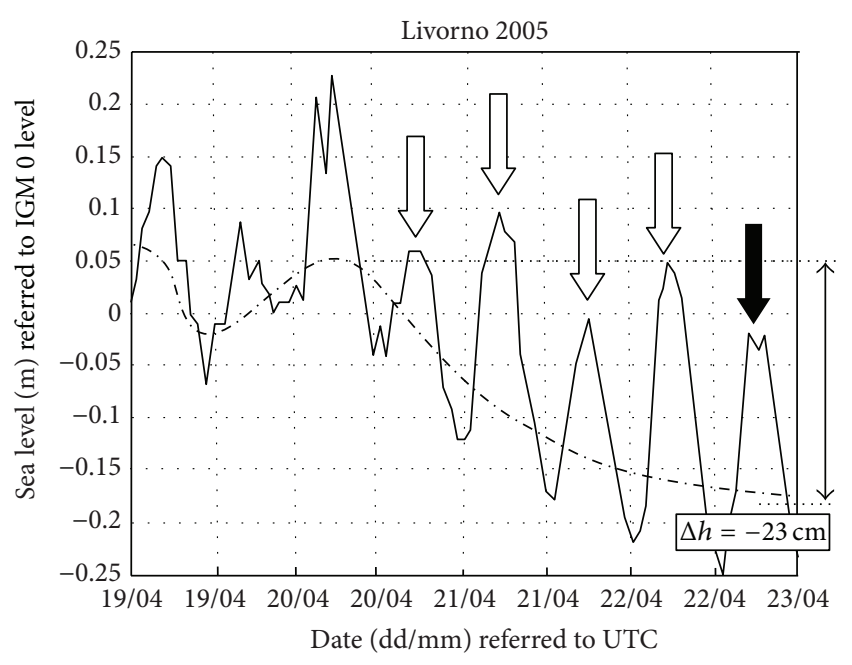

- Mareographic signal

-. . LP component $10^{-5} \mathrm{~Hz}$

FIgURE 13: Sea level variations in Port of Livorno (original signal and its low pass component in dotted line) (image from [15]).

acoustic subsystem. In this scenario, the task performed by the acoustic subsystem could be developed by the magnetic subsystem that should be able to reconfigure itself to close a possible acoustic gap. An example of the above situation could be revealed analyzing the sea level variation produced by the meteo-tide event analyzed previously in the entrance zone during the phenomenon. Analyzing the bathymetry of the zone, it is possible to identify a region in which the acoustic subsystem could be placed without contraindication and in which with the integration with two segments of magnetic subsystem the barrier could provide a complete protection (see Figure 10(a)). In quiet conditions, the acoustic subsystem could work properly, and the gap near the docks is covered by the magnetic subsystem (see Figure 10(b)).

During the occurrence of the phenomenon under investigation, the acoustic subsystem could not provide a complete protection of its competence area, and the system should be reconfigured to close this gap (see Figure 10(c)). After the event, the situation goes back, and the zone returns completely controlled (see Figure 10(d)).

Another interesting aspect related to non compensation of sea level variation can be analysed considering water quality control. If a water quality sample has been taken during a low atmospheric pressure event (more or less $-40 \mathrm{hPa}$ ) in which the sea level variation is, for example, $+1 \mathrm{~m}(+70 \mathrm{~cm}$ due to meteo-tide and $+30 \mathrm{~cm}$ due to astronomic tide) in a basin with a medium sea level of about $10 \mathrm{~m}$ cosidering a constant quantity of solute, the solvent will increase by about $10 \%$. Vice versa if the sample has been taken during a high atmospheric pressure event (more or less $+40 \mathrm{hPa}$ ) and the sea level variation is about $1 \mathrm{~m}$ considering a constant quantity of solute, the solvent will decrease by about $10 \%$. The result is that in the first case it could be possible not to identify an anomaly situation while in the second case it could be possible to indicate as an alert a normal situation.

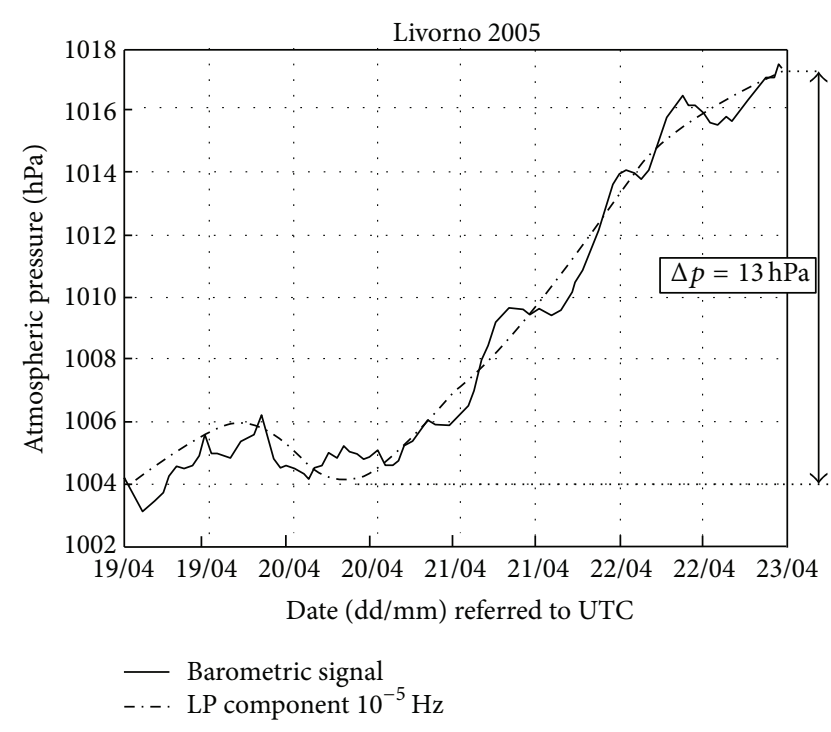

FIgURe 14: Atmospheric pressure variations in Port of Livorno (original signal and its low pass component in dotted line) (image from [15]).

A possible solution could be to report all the analyses to a standard pressure value following the W1000 concept (see Section 2.3.2). Moreover, with meteo-tide forecasting, it is possible to regulate the discharge of waters from industry (i.e., hot water from ENEL-Italian electric energy provider company-establishments), allowing a major water discharge when the sea level is high and limiting the discharge when the quantity of water in sea basin is low.

The last example of consequence due to not considering meteo-tide events in the right way could be performed analyzing the cargo capacity of a panamax cargo ship. If we consider the same variation of the last example with a sea level variation of about $1 \mathrm{~m}$, it is possible to increase the payload of a panamax of about $450 \mathrm{TEU}$ (twenty-foot equivalent unit) equal to more or less an increase of about $17 \%$ of the entire load of the cargo (see Figure 11). At the same, time a free water of about 0.5 could not be sufficient to guarantee a safety navigation for the ship without taking into account meteotide events and its different inverse hydrobarometric factor in constrained areas.

3.2. Port of Livorno. A significant example of harbor waterside management for safety in ship traffic based on meteotide forecasting is represented by the refloating operation of the Moby Rider ship. In April 19-22, 2005, in S. Stefano basin (Livorno port, see Figure 12), the Italian ship Moby Raider stranded for several technical reasons. The Port Authority launched the refloating procedure based on forecasting of astronomical tide highs.

The refloating operation has not succeeded for four attempts (see white arrows in Figure 13) because the action of increase of atmospheric pressure had tide negative effects absolutely higher than the positive effects due to tide astronomical highs. Before starting with the fifth attempt, the atmospheric pressure in Livorno stops its increasing (see 


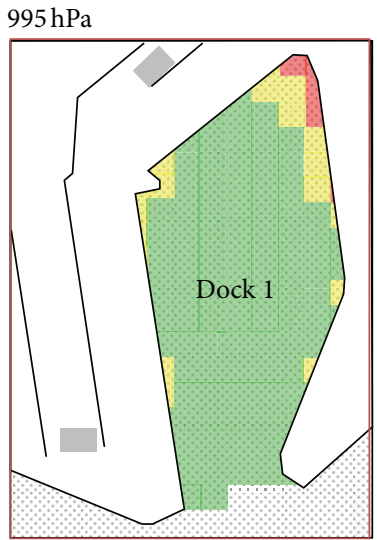

(a)
$1000 \mathrm{hPa}$

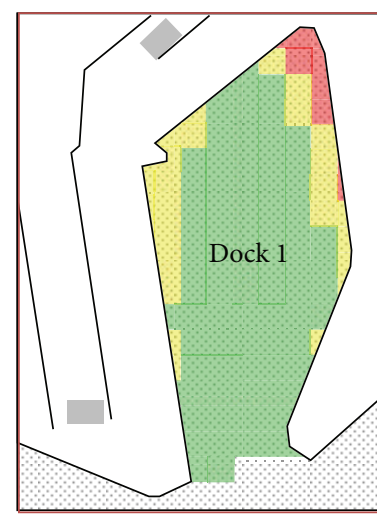

(b)

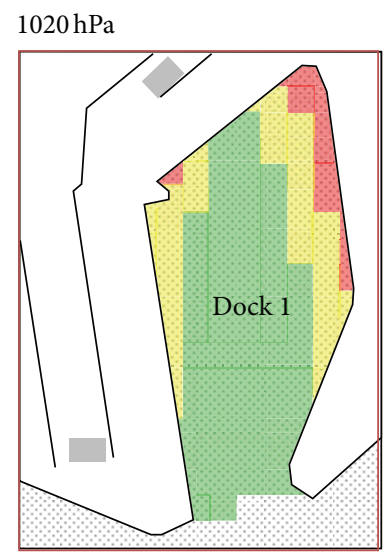

(c)

FIGURE 15: Bathymetric map of a dock in the Port of Livorno depending on the atmospheric pressure ( $995 \mathrm{hPa}, 1000 \mathrm{hPa}$, and $1020 \mathrm{hPa})$; the three colours (green, yellow, and red) indicate three water depth ranges (very deep, deep, and not deep) (image from [15]).

Figure 14). Accordingly, with this phenomenon, the sea level stops to decrease. Under these conditions (without meteotide variations), the refloating was obtained (see black arrow in Figure 13). The refloating operation has had a positive outcome only because the pressure increment has stopped. With the forecasting of the meteo-tide, the refloating operation should be performed at the first attempt executing the operation only at the end of the phenomenon. Moreover, the forecasting could be used to avoid strand events.

\subsubsection{Optimization of a Dock Performance. The knowledge of} $\widehat{J}$ is also very useful in HWSM to forecast the water depth in the approaches and stationing ships knowing only the expected atmospheric pressure. The effects of the pressure variation on the water depth were applied to a dock in the Port of Livorno (see Figure 15). Water depth goes down about $50 \mathrm{~cm}$ consequently due to an atmospheric pressure increase from 995 to $1020 \mathrm{hPa}$, and consequently, $J$ for this event is nearly $2 \mathrm{~cm} / \mathrm{hPa}$; then, the pressure variation changes the bathymetry of the basin, as displayed in Figure 15. A pressure variation could be converted, through $\widehat{J}$, into an expected sea level variation and then into a new bathymetric map. In the design phase of maritime works, it is necessary to introduce the $\widehat{J}$ factor in order to define the height of the marine protection works.

\section{Conclusions}

The paper highlights the importance of metrological analysis of geopotential gravity fields for HWSM and HWQ pointing out safety and security aspects. In the experimental result in Section 2, different areas and situations have been investigated. The above results encourage the research in this field to increase the forecasting capabilities of the system based on meteo-tide analysis. An interesting future work to be addressed could be the constitution of a network of meteomareographic stations able to increase the prediction capability of the system.

\section{Acknowledgment}

The authors would like to thank ISPRA-SMN for the data provided and for the disponibility of its operators.

\section{References}

[1] I. Vilibić, G. Beg Paklar, V. Dadić, D. Ivanković, and S. Čupić, "Qualitative analysis of old and new sea level measuring techniques and their data consistency," IEEE Journal of Oceanic Engineering, vol. 32, no. 2, pp. 428-435, 2007.

[2] D. S. Rosen and L. Raskin, "Wind and wave effects on sea level measurements," in Proceedings of the ESEAS-RI Workshop on Sea Level Observation and Interpretation, Valletta, Malta, November 2004.

[3] O. Faggioni, G. Arena, M. Bencivenga et al., "The Newtonian approach in meteorological tide waves forecasting: preliminary observations in the East Ligurian harbours," Annals of Geophysics, vol. 49, no. 6, pp. 1177-1187, 2006.

[4] M. Crépon, "Influence de la pression atmosphérique sur le niveau moyen de la Méditerranée Occidentale et sur le flux à travers le Détroit de Gibraltar," Cahiers Océanographiques, vol. 17, pp. 15-32, 1965.

[5] F. Mosetti, "Oscillazioni del livello medio marino a Venezia in rapporto con le oscillazioni di pressione atmosferica," Bollettino di Geofisica Teorica ed Applicata, vol. 11, no. 43-44, pp. 264-277, 1969.

[6] C. Stocchino and V. Scotto, "Il livello marino e la pressione atmosferica nel porto di Genova," Bulletin de l'Institut Océanographique de Monaco, vol. 69, no. 1399, pp. 1-10, 1970.

[7] C. Garrett and B. Toulany, "Sea level variability due to meteorological forcing in the northeast Gulf of St. Lawrence," Journal of Geophysical Research, vol. 87, no. C3, pp. 1968-1978, 1982.

[8] P. Picco, R. Bozzano, M. E. Schiano et al., "Marine observing system from fixed platform in the Ligurian Sea," Bollettino di Geofisica Teorica ed Applicata, vol. 48, no. 3, pp. 227-239, 2007.

[9] J. S. Allen and D. W. Denbo, "Statistical characteristics of the large-scale response of coastal sea level to atmospheric forcing," Journal of Physical Oceanography, vol. 14, pp. 1079-1094, 1984. 
[10] C. Garrett and F. Majaess, "Non-isostatic response of sea-level to atmospheric pressure in the Eastern Mediterranean," Journal of Physical Oceanography, vol. 14, pp. 656-665, 1984.

[11] A. A. H. El-Gindy and F. M. Eid, "Long term variations of monthly mean sea level and its relation to atmospheric pressure in the Mediterranean Sea," International Hydrographic Review, vol. 67 , no. 1, pp. 147-159, 1990.

[12] M. N. Tsimplis, "The response of sea level to atmospheric forcing in the Mediterranean," Journal of Coastal Research, vol. 11, no. 4, pp. 1309-1321, 1995.

[13] M. N. Tsimplis and G. N. Vlahakis, "Meteorological forcing and sea level variability in the Aegean Sea," Journal of Geophysical Research, vol. 99, no. C5, pp. 9879-9890, 1994.

[14] P. Y. Le Traon and P. Gauzelin, "Response of the Mediterranean mean sea level to atmospheric pressure forcing," Journal of Geophysical Research, vol. 102, no. C1, pp. 973-984, 1997.

[15] O. Faggioni, M. Soldani, G. L. Piangiamore et al., "Harbour water management for port structures and sea bottom design, coast proximity navigation management, water quality control," in Proceedings of Mediterranean Days of Coastal and Port Engineering, Palermo, Italy, October 2008.

[16] C. Wunsch and D. Stammer, "Atmospheric loading and the oceanic "Inverted barometer" effect," Reviews of Geophysics, vol. 35, no. 1, pp. 79-107, 1997.

[17] J. Willebrand, S. Philander, and R. Pacanowski, "The oceanic response to large-scale atmospheric disturbances," Journal of Physical Oceanography, vol. 10, pp. 411-429, 1980.

[18] R. M. Ponte and P. Gaspar, "Regional analysis of the inverted barometer effect over the global ocean using TOPEX/POSEIDON data and model results," Journal of Geophysical Research, vol. 104, no. C7, pp. 15587-15601, 1999.

[19] Aviso and PoDaac User Handbook-IGDR and GDR Jason-1 Product, SMM-MU-M5-OP-13184-CN, 4.1 edition, 2008.

[20] G. B. Brassington, "Ocean prediction issues related to weather and climate prediction," in Proceedings of the 15th Session of the Commission for Atmospheric Sciences, Seoul, Republic of Korea, November 2009.

[21] I. Moon, "Impact of a coupled ocean wave-tide-circulation system on coastal modeling," Ocean Modelling, vol. 8, no. 3, pp. 203-236, 2005.

[22] P. Lynch, "The origins of computer weather prediction and climate modeling," Journal of Computational Physics, vol. 227, no. 7, pp. 3431-3444, 2008.

[23] P. Lynch, "Weather prediction by numerical process," in The Emergence of Numerical Weather Prediction, pp. 1-27, Cambridge University Press, 2006.

[24] American Institute of Physics, Atmospheric General Circulation Modeling, 2008.

[25] H. Hughes, Model Output Statistics Forecast Guidance, United States Air Force Environmental Technical Applications Center, 1976.

[26] D. L. Best and S. P. Pryor, Air Weather Service Model Output Statistics Systems, Air Force Global Weather Central, 1983.

[27] D. J. Stensrud, Parameterization Schemes: Keys to Understanding Numerical Weather Prediction Models, Cambridge University Press, 2007.

[28] T. N. Krishnamurti, "Numerical weather prediction," Annual Review of Fluid Mechanics, vol. 27, no. 1, pp. 195-224, 1995. 

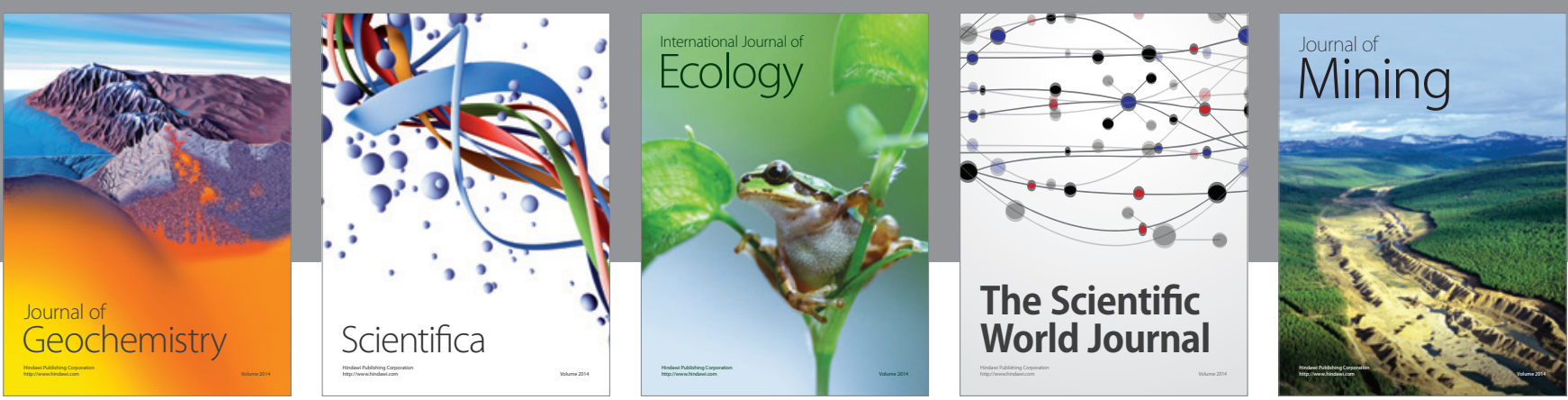

The Scientific World Journal
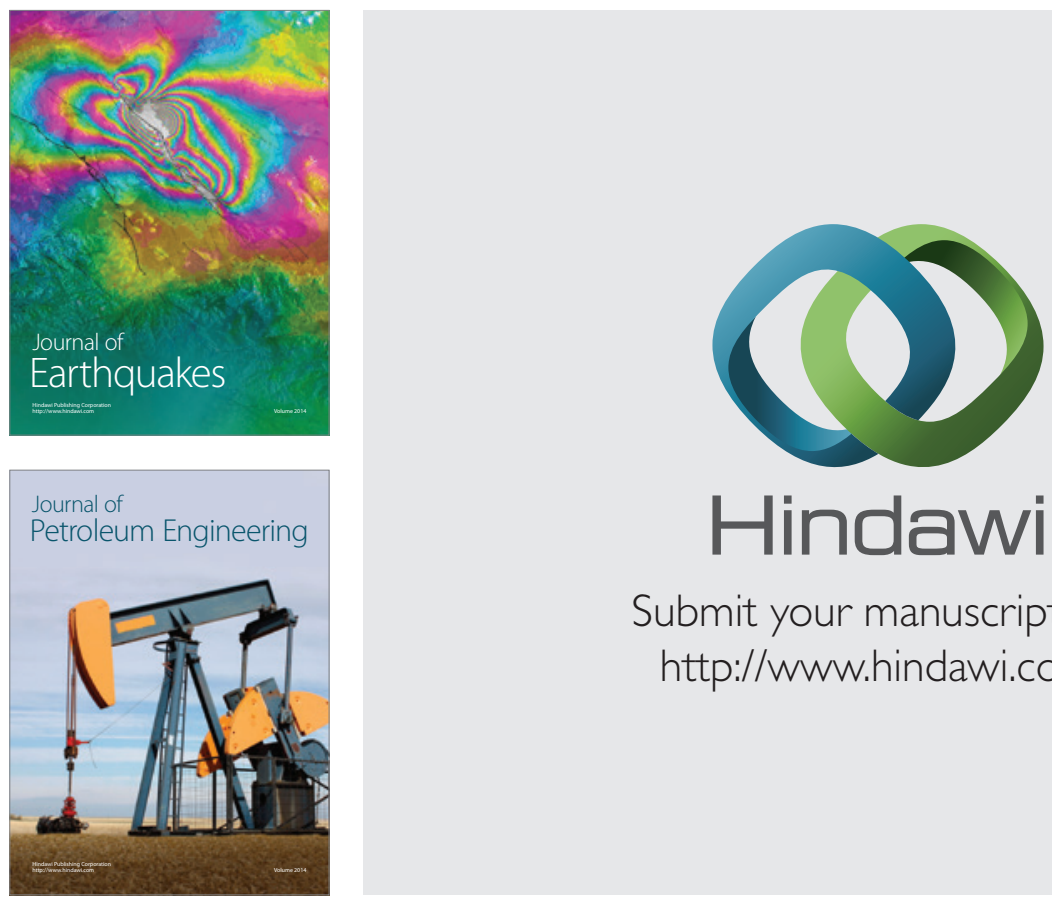

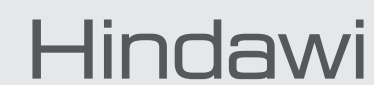

Submit your manuscripts at

http://www.hindawi.com
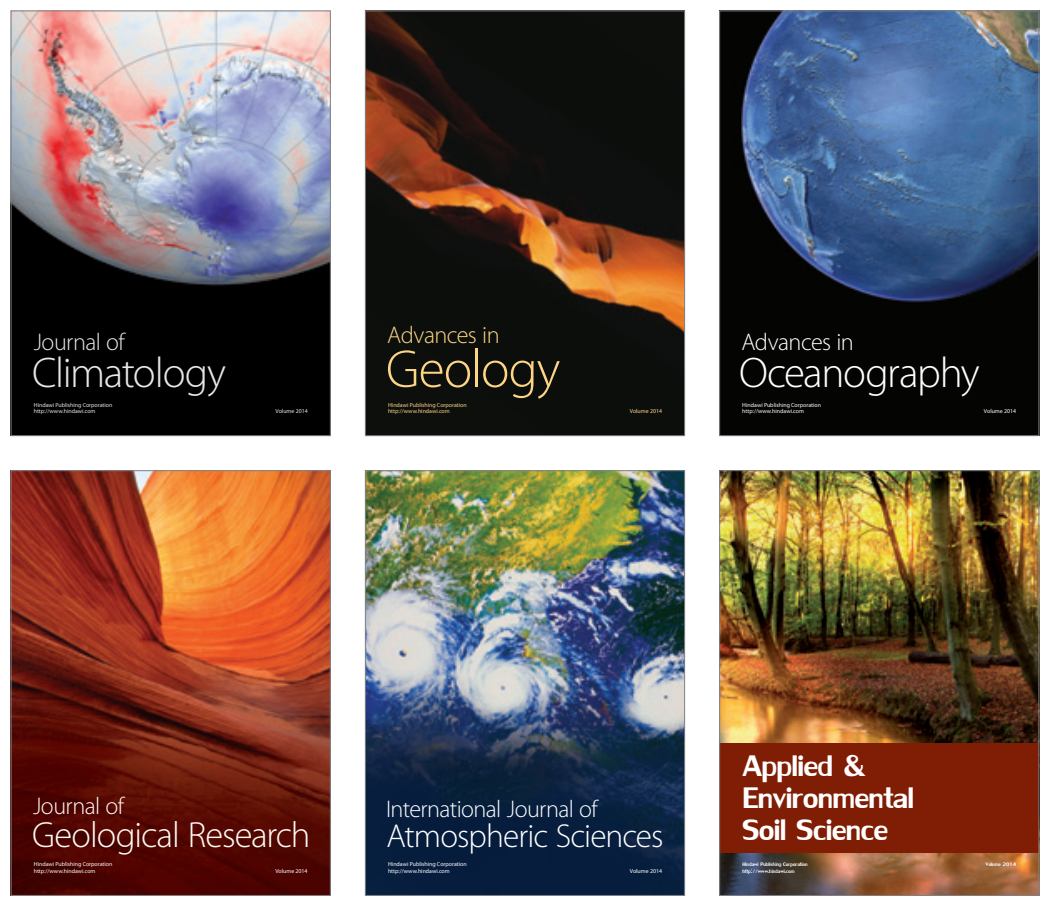
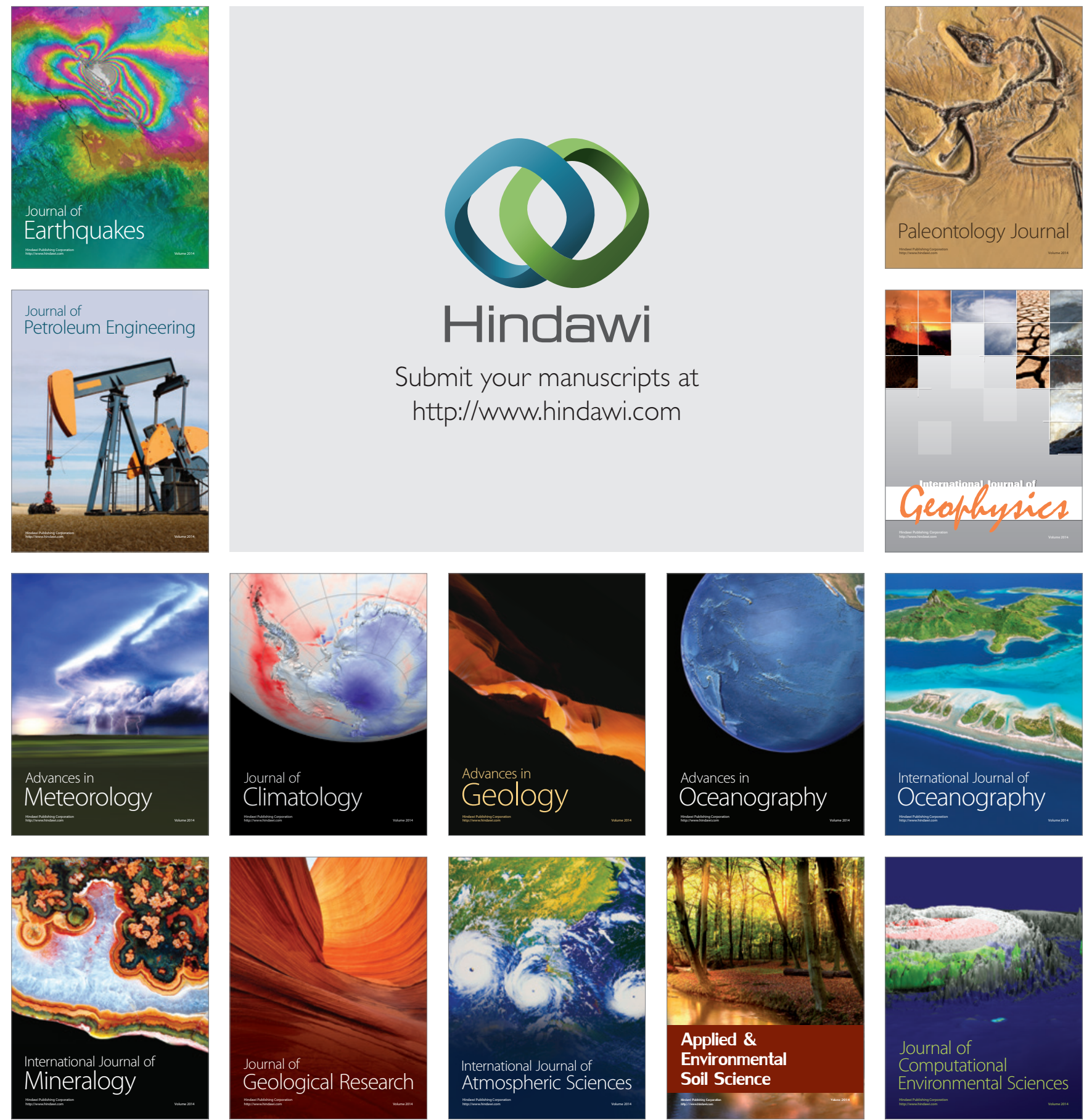